\title{
Author Spotlight: Lisa Fralleone
}

\section{Lisa Fralleone ${ }^{1}$}

Accepted: 6 July 2021 / Published online: 31 August 2021

(c) The Author(s), under exclusive licence to Springer Science+Business Media, LLC, part of Springer Nature 2021

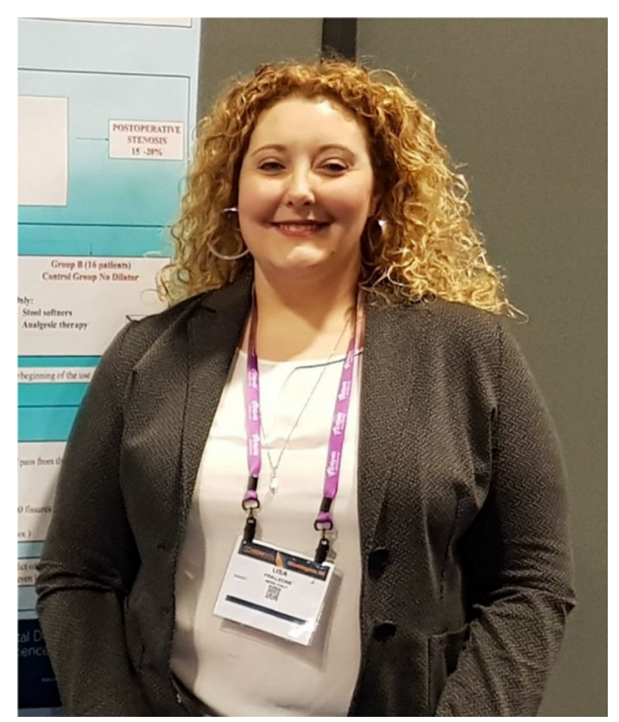

Dr. Lisa Fralleone is currently a 5th-year surgery fellow at the University of Rome "La Sapienza".

She will be an academic surgeon at "La Sapienza" following her graduation in November 2021.

Her clinical and research interests include colorectal cancer, proctologic diseases and endoscopy.

Publisher's Note Springer Nature remains neutral with regard to jurisdictional claims in published maps and institutional affiliations.

Lisa Fralleone

lisa.fralleone@tiscali.it

1 Department of Surgical Sciences, Sapienza University of Rome, Rome, Italy 